\title{
Critical Interpretation: A Comparison of Two Ethnographies
}

\author{
Edmund V. Sullivan
}

Ontario Institute for Studies in Education

\author{
Sergio Martinic and Horacio Walker \\ Centro de Investigación y Desarrollo de la \\ Educación
}

Sullivan (1984) outlines some core features of critical interpretative study. The first is the incorporation of intentions of actors into social inquiry. The second feature (not excluding the above) is to locate these intentions within concrete structures of social power. What distinguishes critical interpretation from other types of qualitative inquiry is its express emphasis on the presence or absence of social power. Why the use of the term interpretation? It is our position that human action is intentional and that intentional acts have a sign quality which makes them expressive. (Thus when we use the term "human expression" it is indicative of the sign quality of human action which makes them expressions for others.) Being expressions means that they are subject to interpretation. Interpretation is open ended and therefore human action is subject to multiple interpretation.

It is our contention that critical interpretation differs from other varieties of social inquiry labeled qualitative, interpretative, phenomenological, and so forth, in its emphasis on the dual nature of human agency (intentionality) and its corresponding dialectical polarity structure (Giddens, 1979; Sullivan, 1984). Giddens (1979) sees the basis of structuration as a recursive action in the development of social life. Thus it is a contention within a critical interpretative framework that human agency and intentions must be seen in a structural totality of social life, and within it, special aspects of social power are highlighted. Three such structural possibilities are the structuration of economic structures, the structure of gender, and that of ethnicity. Economic systems are systems of social relations designed for the exploitation of the environment for purposes of survival. Historically, these structures have varied immensely; the two dominant forms today are capitalism and socialism. All of these structures have within them enclaves of social power which can enhance or detract from human agency (intentions). It is the task of critical interpretative inquiry to illuminate the range of social power embedded in the above structures. One of the problems encountered in interpretative inquiry is the tendency to collapse the agency-structure dialectic. One extreme is the inflated emphasis on 
human agency seen in voluntaristic theories where freedom from structure is emphasized. The other extreme can be seen in deterministic theories where voluntarism is downplayed and social structures are emphasized (Sullivan, 1984). We wish to avoid the pitfalls of the above extremes. In this article we will describe two ethnographic studies. Our intention is to compare them by the yardstick that we have labeled critical interpretation. The first study to be described was carried out by the third author (Walker, 1986). It is an ethnography of the community mobilization by a women's soup kitchen in one of the popular sectors in Santiago, Chile. The second is an ethnography done in England which focuses on violence at football games. It will be the task of this present study to show how these disparate ethnographies can be fruitfully compared.

\section{The Soup Kitchen Study}

This study, entitled "The Transformation of Practices in GrassRoots Organizations: A Case Study in Chile," used an ethnographic approach to evaluation in the study of a soup kitchen's organization of social practices in Puente Alto, a county of metropolitan Santiago. Like many of the soup kitchens of its kind in present day Chile, it constitutes a concrete response to the extreme economic conditions that are currently being endured in popular sectors in Chile under the military regime of Augosto Pinochet. The soup kitchen is a community project organized by a group of women in a popular sector with the help of a church agency and with the sole purpose of providing for people living in marginal economic conditions. The name we will use for this specific soup kitchen is the Maria Goretti Soup Kitchen.

In the Chilean context, the soup kitchen work that we are about to describe is a popular education effort. By popular education, we mean the educational practices that are developed when people at the grass roots levels organize themselves for survival purposes. These efforts are developed beyond the boundaries of formal schooling. A soup kitchen is just one of myriad forms of these popular educational enterprises. Taken as a totality, the soup kitchen can be considered as part of a social movement (Martinic, 1984). The following is a brief description of the Maria Goretti Soup Kitchen. It is constructed by Walker (1986) but is, at the same time, a story using the participants' own words.

This olla comun (soup kitchen) took off several years ago. In those days it was a comedor (a soup kitchen only for children) for 32 children. It was started by a Yugoslavian nun. She helped us through a priest. They brought us groceries and milk for the children. None of the nuns could continue with us and they appointed an encargada (staff person in charge of the program appointed by church authorities). She was a person who worked for the community. At the time we started working with the Vicariate and Caritas. They gave us lots of groceries. But what happened, things didn't arrive at the comedor, but the encargada's 
home. She left us things measured, the oil, the sugar, everything. The encargada took personal advantage of the situation. She would never let us go for the groceries, she always went with her husband, since her husband had a truck. She didn't let us go to meetings either, she went by herself until she was required to attend with an executive. What happened is that the mothers started to get suspicious. So then we elected an executive of three mothers, who started to go with her to the meetings which were held there in the church. For the first time the mothers started realizing that meetings were held, that other things could be done. Then the struggle began to hand over the comedor to the mothers. At that time we were not as many as we are now, we were like twenty mothers, but we had about forty children in the comedor. When we started with the encargada none of the mothers agreed because we were used to working with the nun. The encargada was a mother who has a huge house on this same street, a mother who for us was not equal. But because we had to have an encargada, and the encargada was chosen by the Church, we had to accept her, not very happily.

Then the struggle began for the control of the comedor by the mothers. When the church representative resigned, she also gave up the place where the soup kitchen was located. We were left with our hands tied and had to start looking for a space and a shack. The parish priest donated half the money to buy the shack and we found a lot where we had to pay rent.

Many mothers withdrew from the group for the simple reason that they thought they were going to be worse off because it was as if the mothers already got used to the encargada and thought they would not be able to struggle by themselves to get the comedor going.

Then, soon more people started joining once they saw that things were working. The ones who participate here are mostly from the Irarrazaval area. 'The same senoras that know us are the ones that make contact with us and ask to join the olla. We had struggled for a long time as a comedor, when we started talking about forming an olla comun. But we didn't know that the olla comun had been operating for a long time because all the mothers brought something. We never planned to have the first olla comun in this county, because we, as comedor, started becoming an olla without knowing that we were already an olla.

We continued our struggle with raffles, the onces (gatherings where tea and biscuits are served with the purpose of collecting money), with dances. We have had problems with bad executives such as when we had a dance, we collected some funds and they were lost. We have collected some 35,000 pesos ( 35 dollars) with such sacrifice and the President suddenly came with this story of how she lent the money to a retired woman. She told us that when she got to the retirement allowance she was going to give the money back.

Now we work well, all together. We have a fine executive. The president has been in charge for four years and is very correct. There have been several secretaries and treasurers though. This year we elected a new secretary and treasurer. The three of them work very well together as executive. Things are collected at the market and some shops give us groceries. Every mother knows she is to bring a daily contribution: carrots, potatoes, onions, whatever. Besides that, the Vicariate gives us three provision allotments every month: milk, flour, and a third, that varies, spaghetti, rice, or beans. Alicia from the Vicariate works with us. But she doesn't come all of the time. Sometimes she comes for a while to the meetings. We have to turn in our questionnaires to her with the number of participants so that they can give us the alimentos each month. If we have problems we can talk them over with her but many times we solved them by ourselves.

We function well although at times some of the mothers get mad. There are times when they don't have contributions, because the majority work in $\mathrm{POJH}$ and 
have more than one child; they all have three, four, five, seven children. Then the mothers can't bring a contribution every day, although it is an obligation. We take turns cooking, two mothers for a whole week. Now we are many. At the present time we are thirty-one because now food is given even to the husbands. We meet once a week, every Tuesday. In the meetings we talk just about anything. The executive explains everything straight out. It is an obligation to attend the meetings. A person who misses three times without a good reason gets kicked out of the organization. It is the only way.

We take wagons around on pick-ups. We, the women, do everything, that is, we are alone, we don't have many men. Since we started as a group we have been independent. We don't like men to participate, that is, we are used to struggling alone. If the roof needs to be fixed, we just fix it; just women, we have done it before. We have had storms, roof boards flying off and we have had to fix every. thing. We climb on the roof and nail them down while someone holds the ladder. When we started working as an olla, it was when the political stuff was starting up again, when the protests began. We didn't have anything to eat, all the Senoras, sometimes, didn't have even breakfast for the children. We were suffering from everything the government was doing, we started protesting. Because of that we got a bad reputation, we have been called different names and accused of being a political Centre and things like that. But now people have awakened more, I mean, we were the first to start to protest in the area. There had never been protest in this area. This group of ours is very hard working. It participates in quite a few things such as land takeovers, training workshops and other workshops.

Another difficulty we have had is that people are ashamed to participate in olla. Sometimes they don't have anything to eat, but they don't approach us. Sometimes our husbands don't like to see us involved in these things and even less in the olla. (pp.15-17)

On the basis of the participant observations and the interviews, the study moved in a systematic direction of interpretation that we are naming critical interpretation. First, there is an attempt to identify the main contradictions which underlie the soup kitchen's story. Second, there follows a procedure of multiple interpretation which we feel is unique to critical ethnography. The soup kitchen is not only interpreted by the CIDE researcher, but also by other grass roots organizations. Finally, the interpretation is broadened to account for the analysis of class and gender that appears operating uniquely in this setting. Thus the microanalysis of the organizational practices is related to the macrostructures in which they are situated. Central to this context is the analysis of popular education as a praxis of transformation of organizational practices (Walker, 1986). Thus this study self-consciously goes beyond an ethnographic account to a level of analysis that we are calling critical interpretation or, if you will, critical ethnography. We call this process a "double hermeneutic":

By this notion, we mean that all systematic interpretation is two-tiered. It expresses the dialectic of distance and relation, as follows. First of all, systematic interpretation must be related to a particular cultural form and its unique expression so that action may be appreciated from the 
point of view of the conscious intentions of actors (i.e., relation). Second, systematic interpretation must be done at enough distance from specific cultural expressions to provide critical feedback on these expressions (i.e., distance).

(Sullivan, 1984, p. 115)

Walker (1986) does this in several different ways throughout his thesis but for our purposes we will only consider four major areas of contradiction that he develops as part of a critical interpretation of this particular popular education effort. These are developed on the basis of the intensive ethnographic work, but they are not part of the discourse of the participants involved. We will focus here on these contradictions as one way of demonstrating a facet of what we are calling critical ethnography. The four contradictory areas that Walker elucidates are as follows: (a) a contradiction called dependence/independence, (b) social versus traditional explanations of women's oppression, (c) politization versus apolitization and, finally, (d) organization versus disorganization.

\section{Dependence/Independence Contradiction}

A critical interpretation goes well beyond the level of first person accounts and participant observation. What is unique about the idea of a critical interpretative account is that there is a systematic attempt on the part of the investigator to code relationships of domination and also focus on aspects of social organization that impede the agency and freedom of individuals and groups (Sullivan, 1984). In this present study, one major aspect of critical interpretation is revealed in an area that is labeled the contradiction (which is identified through the first person accounts) of dependence/independence. In the particular instance of this soup kitchen one finds a constant theme that recurs, that is, how agencies and key people are the point of contradiction in the development of authentic communities. This particular community had to deal with a religious community that was extremely helpful in getting this organization started, international agencies of aid, and in particular, a Solidarity Church related agency labeled the Vicariate. At the beginning there was a considerable amount of go-between work in the community and these outside organizations. There was a particular woman called the encargada who was initially the liaison and coordinator between the external agencies and the community. She very quickly became the focal point of criticism for the other women in the community when a consensus developed among the women that she acted arbitrarily, in an authoritarian manner, and without consultation with the others. Part of the initial quest toward more independent initiatives is seen in the fact that the women in the community confronted the encargada and eventually eased her out of this role. This initiative toward a more independent and egalitarian set of relationships took place within the group proper. It should be pointed out that the pressures toward independence were a two way process 
in most instances where this particular community related to the Vicariate. These were relational moves between the group and the external agency. Summing up this tension, Walker (1986) notes how the Vicariate gradually took over the comedores program, with their own staff replacing the local coordinating role of formal church structures which were in place at the start. The effort was the gradual winding down of the comedores and their transformation into ollas communes. Alicia tells about this process of transformation in the community:

We (the solidarity group from east Santiago Vicariate) organized summer camps in 1978 for children. Several women from different groups went to cook at the camps. We had sent them away from

Santiago, to the beach, for a week. As a result a sort of intercommunication was formed among groups and experiences. Ideas were exchanged and the groups started realizing how backward they were from an organizational point of view. The women started realizing what they could do by themselves. I believe that there has been a whole process of self-affirmation as persons and as a group as well. They became aware of their abilities to manage an organization, even the most organized have the problems that they have. (p. 20)

In summing up this process of achieving independence from formally dependent situations in this community, Walker stresses that

the struggle for autonomy did not come just from the Vicariate but also within the group. For this reason I see it as a dialectical process in which the idea of transformation is developed simultaneously within the group and within the Vicariate. When the group rid itself of the encargada it organized itself internally, broadening the members' participation. This was a definite step towards more independence. They started bringing their donations and supplying parts of the food on their own. As the women state in the story: "We never thought we were going to become the first olla comun in the country, because we, as comedor, started turning it into an olla without knowing that we were already an olla." (p. 21)

\section{Social/Traditional Explanations of Women's Oppression}

Walker (1986) identifies gender as one of the fundamental interpretative categories of his study of this soup kitchen project. Gender is identified as central because it relates to why and to what extent women participate, and why men do not participate in organizations of community survival such as soup kitchens. Additionally, gender helps in an interpretative understanding of some of the fundamental problems that exist within this organization's life. The interviews as a totality demanded that the researcher view gender as essential to the interpretative understanding of this organization. This dimension of interpretation assumed salience in this research effort, not only because the vast majority of the members of this organization were women, but also it was felt that being a woman was 
related to specific practices which gave this group a specific character.

What is telling about all of the interviews with these women is the fact that their relationship with their husbands or convivientes had a history of pain and frustration. Although each interview with these women had its unique characteristics, all relationships with men were interpreted as extremely problematic. Thus the participation of women in this organization is seen as a struggle, sometimes because of male opposition, sometimes because of exploitation at home. A brief description of a conversation with Senora Birtha, a member of this group for six years, sheds light on this question:

Interviewer: And do men participate? Senora Birtha: No. We are only women. When there is something to be fixed, then their husbands come to help, to hammer nails. Interviewer: Would you like them to participate? Senora Birtha: No, because we are used to being by ourselves. It would be uncomfortable to be with men because we have been alone for many years. Interviewer: And why would it be uncomfortable? Senora Birtha: Because like this, being among women, there is more trust than with men, I think that would be lost. (p. 22)

There are three men that are affiliated with this soup kitchen and their reasons for participation are important but will not be discussed here. Suffice it to say that in this group they are not in attendance at social gatherings and are more in that type of assistance relationship to the women organizers already discussed. Men's absence is not accidental. Women in this group self-consciously exclude men on important occasions. This was done when a trip was organized to a beach at Puente Alto, which constituted a few days' vacation. In the preparatory discussions for this trip, it was decided by total agreement among the women, that no adult men were to be allowed to go. This instance is interpreted by Walker as part of a more generic gender problematic that is felt to exist at two levels. The first is in the more private sphere (relations with men and motherhood) and the second is in participation in activities outside the home. Walker summarizes this problematic as follows:

Understanding the conflicts experienced in these two types of situations differ from women to women. Some have individual, psychological and even religious explanations of women's oppression. A minority understands the relationship of institutionalized oppression to the social construction of gender relations. These contradictory views bring about conflicts in the group. However, it is interesting to note that sometimes the resolution of conflict satisfies everyone. For example, while the understanding of why men must be kept out of the group differ significantly from group to group, excluding men satisfies all of them, given that all of them experience in one way or another a basic oppression. (p. 24) 


\section{Political/Apolitical}

The awareness of gender relations as socially constructed has fundamental political implications for the basic definition of what constitutes the political sphere. One is the reconceptualization of being political as entailing the questioning of the dominant power relations in the home. These issues were not unrelated to the survival needs in these homes that have been created by the military junta under which they are presently living. As one of the older participants in this soup kitchen recounts, the political focus started in 1983 when there were the first major public challenges to Pinochet's iron rule since the coup:

Then politics started too, because the demonstrations began. We hardly had anything to eat. Most of the senoras couldn't give breakfast to their children. We were suffering from all the government was doing. We started protesting. Because we went out protesting we got a bad reputation. We were called different things and some people said that the olla was a political centre and things like that. Even sometimes, mothers who really needed us, who didn't have anything would not go into the olla centre to put food into their pots for home for the simple reason that the organization was already tainted with the label political. They blamed us for anything that happened in the neighborhood: power blackouts, passing out leaflets and everything. We were the first to start the demonstrations in our neighborhood. A group of women from the soup kitchen went out to protest, no one had protested here before. The first day we went out with pots, but the pots got damaged so we decided to use metal barrels and we beat on them with pieces of steel. Now other people in the area are participating too. The police didn't come for the first demonstrations. But the police and the military came for the last two (Sept. 4-5 and October $27-28,1984)$. They started throwing tear bombs at us. We had some molotov cocktails prepared in bottles just in case they decided to come into our houses. We had the centre open but with the doors closed. (Walker, 1986, p. 26)

Here it must be noted that this explicit discussion of this organization's activities as political is not typical. Explicit statements such as the above were made spontaneously by a small number and it was the contention that the researcher should not actively pursue these topics because he felt that talking politics with an outsider was dangerous. However interesting questioning might be, the researcher restrained himself from this type of intrusion on community sensibilities. As expressed in the interviews, the political/apolitical contradiction is seen in conflicting views regarding members' participation of the soup kitchen in activities against the dictatorship. There are also conflicting views on the development of group activities such as discussions to raise awareness about government oppression and the need for organized resistance.

The foregoing discussion of the conflicts between political and apolitical reflects a restricted conception of the political sphere. The lack of an articulate discourse or of participation in traditional 
political action (e.g., party politics) does not denote a lack of political consciousness or political activity. Walker contends that for this particular organization and others of its kind, political action can be seen in the everyday struggle of the organization under the present larger political conditions under the dictatorship.

\section{Organization/Disorganization}

In the context of present day Chile, the issue of organization in one's social life is one of suspicion. Under the dictatorship, simply being organized is a struggle because it is repressed frequently by the government. According to the municipal authorities (the local representatives of the state) Church related organizations are seen as a threat. The only formally permitted organizations are those sponsored by the state authorities. No financial or technical support is given to other groups.

Overall, the organizational process is a struggle against apathy. The majority of people in popular sectors do not belong to organizations such as the soup kitchen described. What is important for our purposes is that entering an organization is a decision that implies abandoning the "majority attitude" of passivity. Furthermore, joining a soup kitchen not only requires exchanging passivity for action, but also overcoming social stigma. Within the organization, democratic relations struggle against authoritarianism, and the active participation of some is contrasted with the passivity of others.

The idea of organization for this soup kitchen has as one of its features the idea of strong leadership. The head of this organization, Senora Meche, is described by one of the members. Senora Meche has been a leader for the past five years.

Well, Senora Meche comes in and says "good afternoon to everyone, we are going to start the meeting, I would like you to tell me how the food was this week." And all of the Moms respond, lets say it was good, and in the meeting we make all of the decisions that we need to resolve problems. She (Senora Meche) gives her opinion and we all respond. If anyone has any doubts we get to say that we have doubts and then we reach agreement. (p. 22)

Here, strong leadership is seen in the ability to conduct meetings where the group is able to achieve consensus on a problem being discussed. And, although the greater the agreement, the better the organization is, participation in the process of agreement is highly valued. People are expected to express their opinions and doubts. They are also expected to act on behalf of the organization through concrete activities. Among the main activities involved in being organized are attending the Tuesday meetings, speaking up at the meetings, and spreading the word when schedules are altered. There is also taking turns cooking, participating in raffles, occasionally 
attending Vicariate meetings, and so forth. What is important is that these activities seem to be done by all members. Given the hostile response of the authorities to any type of organization, these types of organized participatory responses can be said to exist in atmospheres where organization and apathy are the norm.

Thus we have highlighted here the participants' social practices in terms of how they can be interpreted to exist from the point of view of an outside researcher as a cluster of contradictory relations. By focusing on these contradictory relations, there is an attempt to highlight how organizational practices are dynamically developed and not mechanically reproduced. The reproduction of practices has been examined in relation to a structure of domination within which these practices operate. Both social and gender relations are discussed as relationships of domination, thus a critical interpretation (see Sullivan, 1984). The question of power is first formulated at the level of everyday life (i.e., participants' accounts), then from these accounts there is formulated by the researcher the "story" of the group. Interpretations of this story beyond the narrative level of the participants is then done by other grass roots organizations as well as the researcher's interpretative intervention.

The advantages of this multiple interpretation were said to be the following. First, the interpretation of organizational practices must be culturally immersed. The fact that other organizations shared the same socioeconomic background helped ground the researcher's own interpretation. It was felt that the researcher's interpretation could be extended and supplemented by groups that were sympathetic to the soup kitchen's struggle. Second, taking into account the other organizations' interpretations was a way to understand how the organizational experience of each of the groupinterpreters influences the sense each makes of the Maria Goretti story. The construction of meaning is illuminated by their practices. Therefore contrasting experiences enrich the interpretation. The gender issue, for example, as seen by the different group interpreters, allows the researcher to situate its significance within a cultural perspective which transcends the organizations dominated by women as in the soup kitchen. The multiplicity of organizational experiences and the way they relate to the construction of meaning of someone else's practices was said to aid in situating Maria Goretti in broader terms (e.g., a movement). Third, a multiple interpretation was also felt to be necessary for the idea of process. Taking the story to another group brings up new questions expanding the researcher's perspective.

In summary, the interpretative process started with the problematic description of the soup kitchen's practices and then went on to discuss, in a depth that is not captured in this present treatment, a critical structural analysis which linked those practices to social relations. What we have done in this present treatment is look at 
structural features of a specific community project which go beyond the narrative accounts of the participants, yet use this narrative base for discussing what are considered important dimensions which have contradictory underpinnings for the life of one community organization.

\section{A Comparative Analysis}

First, in the action research that we have been characterizing in the "systemization" project and specifically the Soup Kitchen study, there is clearly an emphasis in studying participants in the project with the idea of "collective action" as the totality within which individual actions receive or are denied significance. This is important as a point of emphasis, because we see the direction of qualitative research in a North American context as underemphasizing the collective when participant accounts are being analyzed (Sullivan, 1984). Thus in the Soup Kitchen study, the categories of contradiction such as dependence/independence, social/traditional explanations of women, political/apolitical, and so forth, are not formulated specifically around simply the personal life history of the participants but are formulated with a view to understanding the collective striving of the group as a whole.

A second example that we would like to bring to the reader's attention for illustration and comparison comes from the work of Harre and Secord (1971), and of March, Rosser, and Harre (1978). Their work represents the first systematic attempt to critique mainstream positivistic research and also provide a sustained rationale for an alternative set of principles. They label their work ethogeny and within part of this perspective one sees a place for first person accounts and participant observation. At the level of critique of mainstream research and theory, it is evident that there is a clear indication that we share much in common with their analysis. Given some of these complementarities, it is very important to also accent differences because it is clear, from some of the subsequent work of Harre and colleagues, that the pursuit of an ethnographical or phenomenological emphasis does not necessarily move one into the orientation that we have been labeling critical interpretation. This comparison will be important because it dramatizes important differences between what we consider to be diverse approaches to ethnography even when they share common criticisms to mainstream research. The following example is given from the work of March, Rosser, and Harre (1978) because it clearly illustrates that ethnography and phenomenology do not necessarily lead to a research strategy with emancipatory intentions. This is not to say that there is a clear right and wrong direction for ethnographic work, but rather that alternative directions can be taken that must be examined on their own merits and also in comparison. The comparison that we wish to make here is to help the reader see that critical 
interpretation is one interpretation among other ethnographic approaches and must be justified on grounds other than that it provides a different approach to mainstream studies. In addition, it is clear that some of the emanicipatory critical interpretation cannot be accomplished in some of the studies that fall under the rubric of an ethnographic emphasis. March, Rosser, and Harre indicate at the outset that the subject matter of their book is the study of violence and disorder as it relates to problems that are created at football games in Great Britain. Given the recent tragedy in Belgium, where a number of Italian football fans died in violent encounters with British football fans, this cannot be an inconsequential topic for social inquiry in a British context. This study predates this dramatic event but its social relevance is clearly established as a social problem in Great Britain. This particular study is an intensive ethnography of a group of lower class males who attend these football games. As a comparison with Chilean women seeking to organize themselves for survival purposes, it certainly appears on the surface quite remote. We are not seeking here to compare two populations, but to make some critical comparisons in ethnographic studies given that they may take very different directions after the primary ethnographic work is completed.

\section{The Rules for Disorder Study}

The original ethnographic work for this study was completed at two sites where the participants were able to be interviewed. One of the sites is a school where researchers interview male adolescents about life in the classroom. All of these boys are of working class origins. There is no direct observation in the classroom; the researchers depend instead on interviews to depict life in the classroom. The other site is on the football grounds labeled the Terraces. The ethnographic work here is mostly based on observation and first-person account interviews.

\section{The Football Grounds (Terraces)}

Although many strata of society will watch a football match, this study focuses on working class youth. The researchers maintain that in this setting there is an order known to the police and the youth which demands that specific locations be adhered to by home and opposing fans. The police place themselves as a wedge between the home-team fans' territory and that of the opposition.

Besides interviewing, these researchers made video recordings of the setting. They maintain that the recordings reveal patterns and groupings in which they were able to attribute a number of salient behavioral and social characteristics to the boys. These boys ranged from 12 to 17 years of age and a specific grouping sported "aggro hats." The researchers feel that this setting is not one of disorder but a place where "moral careers" are enacted. In this setting, moral careers connotes a way of "becoming somebody" and is a highly 
structured affair.

The researchers identify six types of moral careers: (a) Chanters or chant leaders, who lead in chanting and taunting; (b) Aggro leaders, who lead in the expression of aggression that is not seriously injurious and who must be courageous, but not foolishly so; (c) Nutters (who number 5 or 6 boys) are individuals whose behavior is considered so outrageous as to fall outside the range of rational action (i.e., goes mad or goes wild). The researchers see a Nutter as one who demonstrates to others the behavior that one should not do, providing proof by negative example. (d) Hooligans are boys whose actions are thought to be worthy of praise. This is contrary to the media's definition of hooligan. Usually their actions cause small damage to property and enrage some members of the dominant culture. Nutters and Hooligans have this in common: they provoke. A Hooligan is a "jester." (e) An Organizer is an older boy who does the management work (gets bases, etc.). (f) A Scapegoat is an individual who receives negative attributions (i.e., someone who is habitually picked on). In addition, Town Boys are a special group in that they are the elders who have graduated to the Rowdy groups. They are less noisy but clearly tough. They are also seen as heavy drinkers.

The researchers suggest that the career structures help explain the social behavior that on the surface appears irrational. They follow a procedure that attempts to elucidate a rule structure which gives some indication that the surface behavior of these boys is not irrational but rule governed according to the moral career that they are following. In looking at the moral careers of these boys they are trying to tease out a "rule structure" that makes a career understandable and meaningful. Their first level of interpretation beyond the narrative is that of a structure of moral careers. Thus one element of their moral careers is seen in a structural light (Sullivan, 1984).

In the 50 interviews with these boys one point recurs: Fights are not random. Aggression ensues in circumstances where fans are able to specify legitimacy for their actions. To summarize the question of rule structure it may be said that: (a) there is a set of interpretative rules (related to territorial rules or foul, etc.) indicating when aggression on rival fans is appropriate; (b) once a fight has started there is a rule structure governing its course; and (c) rules governing the closing off and termination of fights can be isolated. There is a further subtlety within these structures in that the rules can be seen as explicit. Sometimes purposely the researchers altered the account of the participants so as to create a discrepancy. By doing this they felt they would unearth, if you will, the presence of an implicit rule. As the researchers indicate, "by looking at what they say is wrong with the story we can obtain recognition of the rule breaches. This, in turn, allows us to specify what the rules themselves are" (March, Rosser, \& Harre, 1978, p. 11). 
The authors utilize a term called "Aggro" meaning a form of ritualized aggression. The authors contend that up to this point they have stood inside the phenomena and have carefully listened to what the fans have had to say. Their claim is that they have attempted a close scrutiny of the events on the terraces and have attempted to outline what they consider to be the social order of shared meaning that exists there. For the participants their order is outlined to the structural delineation of rule structure. At the end of this structured interpretation they speculate about its limitations: "The existence of order, then, does not in itself guarantee Utopia. The only way of deciding the merit or value of society of a particular order is to the relevance of function to that order" (p. 117). Thus we see here that for the researchers ethnography is a very explicit theory based on structural and functional concepts. As we will note later, this type of direction takes us along a very different path from the emancipatory theory of the Soup Kitchen of which we will say more later. Suffice it to say the differences make for a very different discourse on social organization and its direction. It also will show foundationally how different ethnographies can be when one examines some of the sociopolitical orientations of the researchers and the rationale for their theories and practices.

In the present study, we note that the authors introduce the notion of aggro to flag the fact that foundational elements of this ethnography cannot be understood without functional concepts. By contrast, the Soup Kitchen study has no explicit functional concepts in its discourse. What then does the concern of aggro serve in this theory? In presenting the notion of aggro the authors venture that the rule structure they interpret is seen as "a reason for action." Their use of the notion aggro is to give a functional explanation for action so as to use their theory as a causal theory. Why this is necessary is not apparent and it is perplexing to understanding why they move in this direction because their objectives seemed to appear, at the outset, to be an interest in interpretation and not causation. It is their contention that an interest in causation is necessary for a theory to legitimately have scientific credibility. Using the concept of aggro, we see the authors move from ethnography into a functional sociobiological direction. The functional explanation therefore moves from a conventional order based on rule structures that are generated by the participants' accounts to what the authors call a natural order. In other words, the naturalistic explanation is clearly an account from outside, an interpretative maneuver that indicates the preoccupations of the researchers and not the participants.

This research team now see themselves in a primary stage of what they are labeling "explanation." The adequacy of this move should be judged in two ways: (a) on the basis of its fit with the common sense reality of the participants-in other words it has to go down with the fans when it is fed back to them so they can see themselves 
in this type of description; and (b) in terms of the criteria that are used in the initial interpretation (i.e., moral careers).

The notion of moral careers is the initial framework that is the basis of the prescriptive rules for violence. The researchers believe that it is necessary to go beyond this initial framework to the functional sociobiological framework of ritualized aggression (i.e., aggro). Why? Because they feel it is necessary to discuss the function that aggro plays in society at large. This theoretical jump is justified because if football violence is seen in a larger perspective, this shows that their aggression is part of a more generalized mode of ritualized aggression that is species generated. The authors look at the aggression as a form of ritual (i.e., aggro). The authors define a ritual as having four key elements: (a) a pattern of routines of behavior, (b) a system of signs that convey covert messages, (c) the existence of sanctions expressing strong moral approval or disapproval, and (d) a conventional relation between the action in which the ritual is performed and the social act achieved by its successful completion.

March, Rosser, and Harre (1978) contend that life in the classroom and on the terraces can be functionally catalogued as a form of ritualized aggression (i.e., aggro). They summarize their work as follows:

We have not sought to excuse the football fan or the classroom troublemaker. Instead we have simply tried to show that the events which outrage us are simply a different reality and are capable of being construed in a very different manner. We have tried to reveal social order in events which are traditionally seen as dangerously anarchic. And social order, whether it be in the form of ritual or not, is something that needs to be recognized and seen as having utility and merit. When magistrates and police refer to fans as animals and savages and when teachers are unwittingly engaged in the process of systematic humiliation and depersonalization of school kids, orders are threatened. We may never, given our existing social frames of reference, be able to create systems of schooling that kids regard as relevant to their own culture and socialization. And without doubt, we will be unable to suppress entirely the aggression and the striving to subdue rivals that have been characteristic of young males in all human societies at all times in history. Given this, we must look to ways of managing hostility and violence rather than naively hoping that they will go away. If we expect that there are, from one significant standpoint at least, rules of disorder we might be able to develop management strategies which have far more purpose and effect than those which have currently emerged from the atmosphere of moral outrage and collective hysteria. (p. 144)

\section{A Comparison of Critical Interpretation and Ethogeny}

\section{Similarity of Methodology}

As the reader by now is amply aware, these two studies bear very little resemblance at the phenomenal level. The subjects studied are vastly different along gender and age lines. In addition, there are 
totally different cultural contexts studied. On first look, there seems to be very good reason that any comparison made between these populations is in serious risk of being invalid. It is our belief, however, that certain comparisons between these studies can elucidate some controversial issues that are latent in studies that see themselves as alternatives to quantitative methodologies. It is our conviction that the recent critiques of quantitative methodologies, with their suggestion that they can be supplanted by qualitative methods, is frequently a superficial panacea with vacuous claims. We would hope that the comparisons that we are about to make will help the reader to see that what is being labeled as a qualitative emphasis in research has as many of the contradictions within it as its quantitative counterpart. It is our belief that it is not really fruitful to make a cold and hard distinction between quantitative and qualitative methodologies and that the direction that we have called critical interpretation can combine both qualitative and quantitative methods (Sullivan, 1984). What we will try to attempt here is to demonstrate that the varieties of research strategies that go under the rubric of postpositivistic alternatives can be very different indeed, even when they are using similar research tools (e.g., personal interviews, participant observation). Our present effort is a limited attempt to show that comparisons of this nature can be fruitful both at the level of theory and research practices. With the above in mind, let us now turn to a comparison of the two studies that we have just summarized.

What can be easily seen from both studies just described is their likeness at the "brute data" or narrative level. Both studies have a base level that can be labeled "common sense" language. By this we mean that the discourse at this level can be understood by professional and nonprofessionals alike. Much of the data base is interview material or concrete descriptions of the participants in the study. Here one can see the fundamental similarity in research that labels itself as qualitative in that its basic structure is built on narrative description rather than indexical or quantitative findings. That being said, the similarities stop here and thus make it important to discuss different genres of qualitative research as the two studies herein exemplify. One of the first points of departure is the implicit or explicit political orientation of the research. We will use the term intentionality to classify this dimension.

\section{Intentionality of the Researcher Within the Research Effort}

In our previous descriptions of the two research efforts we tangentially alluded to the intentionality of the researchers within the research effort. It is now important to bring out some differences in bold relief. They account for different directions and conceptualizations that qualitative research efforts take. First of all, the study of the soup kitchen is carried out by a research group that has an affinity relationship with the group they are studying. By 
affinity relationship, we mean that the research team, although different from the participants in education and economic status, nevertheless share many common values as to the direction of the society they are living in. This relationship is quite explicit in the Soup Kitchen study. In contrast, the researchers in the Rules for Disorder study are not in any sense whatsoever on the same moral or political trajectory as those whom they study. Here we have the difference between research for action's sake (see Zuniga, 1986a), and research for the development of new theoretical horizons (Harre \& Secord, 1971).

When one considers the Soup Kitchen study, we see an action research orientation that brings the research effort into a different professional light. The research is not simply to create new knowledge; rather we see in Schon's (1983) words "a new breed of citizenprofessional committed to social justice." There is the assumption that the knowledge arising from this type of effort has the merit of reminding us that knowledge is possible only in as much as popular movements shatter categories of order and thus cause both the social relations and mechanisms of domination to emerge (Touraine, 1981). When one looks at research, it is possible to see the Rules for Disorder (March) study as one that has a radically different orientation from the Soup Kitchen (Walker) study. If the Walker study highlights possibilities for societal transformation, the March study is potent in demonstrating societal maintenance. The research direction of the Soup Kitchen study was definitely sympathetic to the political direction of the participants:

Information gathering for the study entailed four months of observations and ethnographic interviews. This fieldwork was not my first contact with the reality of the poor in Chile and their organizations. My past involvement through CIDE as an educational worker put me in contact with similar situations. I arrived in the field with an idea of what the popular work was about, with prejudices and beliefs. Overall I brought to the study an expanded sympathy towards the oppressed and a deep belief in that justice has to come. (Walker, 1986)

The March study, by contrast, indicates that the researchers are not belief bound. In fact they posit a vantage point that is clearly objective. In making this distinction at this point we do not intend that one is particularly superior to the other. What we will attempt to show is that this difference in orientation has a very marked differential impact on the conceptual constructions that will develop beyond the narrative level of discourse.

From Intentionality of the Research to Differential Categorization

By intentionality of the research we mean the theoretical (epistemological) and normative (ethical) thrust of the research effort. We encounter here a discourse that goes beyond common sense or 
narrative level. It is our belief that this level contains both normative and theoretical directions which reflect the underlying values that the research contains. It is our view that social science is not value free and is therefore subject to analysis on both theoretical and normative grounds (Sullivan, 1984). On this assumption it is interesting to compare the category system developed in the Soup Kitchen with the system developed in the Rules for Disorder study. What is to be immediately noted in the Soup Kitchen study is that the categories beyond brute data are political and dialectical at the same time. Thus we have a system of interpretation that deals in political categories of social power. Independence/Dependence, Social versus Traditional Explanations of Women's Oppression, and Organization are all dealing with social power issues and concrete tensions of a historical nature both within and outside the group. In contrast, the study of football fans moves in a very different direction. Here we see that the researchers are moving from brute data to a grammar or rule structure of group order. Although the rule structure analysis does not preclude social power issues, one can see that the emphasis is on social order rather than social change and moves their analysis to a level of abstraction that is quite different in nature. The study by March, Rosser, and Harre develops a theory that is directed at how social order is maintained in what appears to be a chaotic situation. The researchers attempt to show that football violence has a functional significance for the participants and a structural significance for the larger society in which it occurs. The concept of aggro is developed in order to place human aggression in a societal understanding that views it as a natural part of being human. This orientation can be classified as "sociobiological" in form. Nowhere in this study can one see the actions of individuals as transformative in nature (Sullivan, 1984). For example, Willis (1977), studying a very similar population of working class youth, interprets their aggression as a precurser to social change. We thus see that the normative direction of theoretical concepts can move in quite different directions.

The bias of the soup kitchen is that it is immersed in a formulation that is skewed as potentially transformative in nature. The power of its analysis is its political interest in social transformation. What is lacking in this study is the very powerful influences that the military junta has in maintaining a military and fascist social order. When structural conceptions are introduced which show the difficulties of social change, they are then directed at demonstrating that social change is possible. Thus the emphasis here is on social transformation by researchers who believe that there are compelling social injustices that warrant analysis in tranformational terms. The converse is the case in the football study. The authors, in this study, never question the social order in which they are living and look at aggression as simply an outgrowth of societal living. They never 
ponder that the violence they are observing could be a type of protest or resistance to the larger society in which their participants, by their social class, are rendered marginal. What is clear in the discourse of these researchers is that they do not see the necessity to formulate concepts involving social transformation. The fact that this could be a possible option can be seen in a comparison of this study with the study of Willis of working class boys (Sullivan, 1984). The intentional base is therefore very important in ordering the theoretical direction of the discourse beyond the narrative.

\section{The Issue of Generalizability in Ethnographic Research}

There is an antimony in the style of research when one takes into consideration how one arrives at more general conclusions. In mainstream social scientific research this is accomplished by going from a sample to a population. The question which now arises in ethnographic studies is how does one go from a specific instance to a more general conclusion. March, Rosser, and Harre (1978) feel that whole generalization is hazardous; it nevertheless can be possible under the following conditions:

In the ethnographic approach we follow the example of chemists and anatomists and adopt an intensive design, that is, we undertake a detailed study of a few cases selected as typical. We are sure of the detailed validity of our analysis of our cases. We can only hypothesize that they are typical. Those who would follow the extensive design can be sure their results are typical, but they must hypothesize as to whether the few properties that survive the working of the inverse ratio between extension and intension have an individuality at all. Our football following participants are from one group of fans, supporters from just one local club. With few exceptions, the participants in our study of talk about classroom violence and its accounting are from one school that is graced by the fans. We are inclined to think that they are pretty typical, given our less detached work at other football grounds and what we know of other groups of school children. (pp. 20-21)

The study of the soup kitchen gets at the question of generalizability in a different manner. Recall that in this study the researcher did not only give his interpretive work to the reader. He also solicited other popular groups to make interpretations on the basis of the group story that he had devised at the outset. It must be noted that these groups made no direct interpretations. Their interpretative work was made on the group story devised by the researcher. Hence multiple interpretation here refers not to the ideas of a group of interpreters who engage collectively in the research, but rather to one interpretation which relies heavily on the research of others. Walker (1986) delineates several advantages to this type of multiple interpretation.

First, the interpretation of organizational practices must be culturally immersed. The fact that other organizations which share the socio- 
economic and cultural background of Maria Goretti participate in the interpretation allows me to ground my own ideas in the culture. My immersion in the understanding of Maria Goretti's practices is facilitated by the involvementdistance dialectic of multiple interpreters. On one hand I discuss the story with others (group-interpreters) who are sympathetic to the group's struggle. However, their distance and different organizational context illuminates Maria Goretti's practices, enriching their interpretation. My distance is supplemented by the other's distance (which differs fundamentally from mine). Second, taking account of other organizations' intepretations helps me to understand the way the organizational experience of each of the group-interpreters influences the sense each makes of Maria Goretti's story. The construction and meaning is illuminated by their practices. Therefore contrasting experiences enrich the interpretation.... The multiplicity of organizational experiences and the way they relate to the construction of meaning of someone elses' practices helps situate Marie Goretti in broader terms, that is, in terms of a movement, a project. (pp. 46-47)

What is essential for the reader to see here is the very different motives that these two studies have in establishing wider significance. March, Rosser, and Harre deal with generalization in the more conventional sense, that is, is the population that they have examined typical? We say conventional here because the researchers are attuned to the issue of generalization already established by mainstream quantitative research. As in quantitative research, there is the epistomological issue of the typicality of the study. In contrast, the Soup Kitchen study is interested in questions of generalization on both epistemological and normative (political) reasons. It is our understanding that the political intent of the research on the soup kitchen sets it off from other types of ethnographies so as to be labeled critical interpretation. Thus questions of generalization are contemplated for very different motives. The Soup Kitchen study is couched in questions of generalization that relate to social movements. Thus interpretation plays a fundamental role-epistemologically and methodologically-in bringing people together to reflect on their practices, plan new action, evaluate their activities, and engage in an overall process of questioning the everyday world, in order to transform it (Walker, 1986). Hence interpretation is not neutral. It provides us with the opportunity to reflect on social and cultural reality from a particular position of interest. Therefore, questions of generalization are not put forward in order to see if a particular group is typical of a larger abstract population. The political intent of critical ethnography, as we see it, is to draw lines which differentiate between dominating rich and oppressed poor, whites and blacks, military men and peace makers, women and men. All these different situations in the world are related to specific ways of understanding our own situation. An interpretation of what happens to a given individual relates to an alternative view coexisting with contradictory views held by other groups. There is a conflict of interest between these views. The task of widening the range of a 
study from that of a particular interpretation is to see that group as part of a larger movement in society which has as its intent an interest which challenges oppression. Thus the desire to situate the soup kitchen study in a wider context is motivated by an emancipatory interest in human liberation. That is the normative work of critical interpretation which is absent in other qualitative alternatives such as the March study.

\section{Question of Validity Within the Context \\ of Qualitative Interpretation}

One of the central questions for social scientific research is the issue of validity of interpretation. Although the presumptions of qualitative research have the objective of going beyond the limits of positivistic social science, there nevertheless remains as a central issue the development of collective belief for new types of social inquiry (Campbell, 1986). There is, within this collective belief, both theoretical and practical considerations. For example, on the practical end validity has implications for the funding of research efforts. In an otherwise sympathetic review of popular education efforts, Zuniga (1986b) raises an important caveat for qualitative research. He maintains that, in this area, investigation of action has demonstrated its practical utility, its political significance, but not its "epistemological truth." This question of validation of new methodologies is important if these efforts are able to enter the arena of dialogue with mainstream social research. It is our contention that one must, from the outset, accept the inevitability of dealing with questions pertaining to validation. Given this limit, one must see epistemological validity and adequacy as argument (Sullivan, in press). In this light we must accept the inevitability of conflict of interpretations. The nature of conflicts can vary from situation to situation. One interpretation may be rejected by the participants. If accepted by the participants, it may be rejected by alternative interpreters. This possibility was built into the Soup Kitchen study which not only involved professional researchers: Other popular education groups were involved in the interpretation of the Soup Kitchen study as were the participants themselves. Thus alternatives must be seen as arguments rather than conclusions. All conclusions are therefore negotiable. Within this context, the issue of validity seems very different for mainstream positivistic research. From the mainstream perspective one might consider that this is, pejoratively, soft validity. It is nevertheless our contention that interpretations must entertain alternative interpretation by necessity. To entertain alternatives does not necessarily mean that all arguments must be embraced. Here, we must point out, that we are using the term validity in a restricted sense. A valid argument within this perspective does not connote "verification" (Sullivan, 1984). To speak of verification is to assume that an account's conclusion is true (Hirsch, 1976). Validity from our perspective must, of 
necessity, be more humble in stance, in that one tries to show in arguing an account that the interpretation is plausible. But validation goes beyond mere plausibility. In accepting conflict of interpretations, one does not have to accept that all accounts are of equal merit. Validation demands adjudication of conflicts of interpretation (Sullivan, 1984):

The job of validation is to evaluate the disparate constructions which understanding has brought forward. Validation is therefore the fundamental task of interpretation as a discipline, since whenever agreement already exists there is little practical need for validation. (Hirsch, 1976, p. 170)

It is here that it is appropriate to make a distinction, infrequently made, between understanding and explanation. Ricoeur (1978) contends that understanding and explanation are relative moments in the complex process called interpretation. When interpretative horizons are complementary or identical there is very little need for explanation. Explanation is warranted only when there is a situation of conflict. Thus explanation follows because

\footnotetext{
Understanding calls for explanation as soon as there is no longer dialogue, where the give and take of question and answers permit an interpretation to be verified as it unfolds. When I do not spontaneously understand, I ask for explanation and the explanation that you offer allows me to understand you better. (p. 153)
}

Here we would agree with both Hirsch (1976) and Ricoeur (1978) that validation is a test of our guesses at interpretation following a logic of probability rather than a logic of empirical verification. In a certain sense, an interpretation is an argument for, or advocacy of, a point of view or horizon (Sullivan, 1984). Our contention is that a valid argument is a form of advocacy for a particular interpretation. In advocating a particular interpretation, one brings forth factual evidence for that particular interpretation. Validation, in these terms, can be seen as an argumentative discipline, comparable to juridical procedures of legal interpretation (Ricoeur, 1978). Arguments for an interpretation must be seen in a relative light. In arguing for a particular interpretation, one develops evidence that a particular interpretation is "probable" under these circumstances. When one interpretation is in conflict with another, the better interpretation attempts to show that it is more probable than its adversary under these circumstances.

\section{The Interpretive Argument in the Soup Kitchen Study}

In the Soup Kitchen study the argument that is developed for critical interpretation is that the idea of everyday practices have contradictory relationships which can be seen because it is assumed that organizational practices operate within spheres of contradiction. It 
was a contention in this study that the resolution of these contradictions consolidated the development of the organization proper. It was also argued that organizations cannot be understood from simply first person accounts, that it is necessary to see these organizations in their permanent relationship to external institutions which have a significant relationship in defining their particular practices. The Church, popular education projects, other local organizations, and political parties belong to a support network in which they interact with one another in a mutual reinforcing process. In the Soup Kitchen study, the Church (Vicariate) and popular education projects are seen as the most important sources of aid for grass roots organizations mobilized in the poblaciones after the 1973 military coup.

Looking at organizations as practices in contradiction highlights the group processes in the Maria Goretti Soup Kitchen as simultaneously one of reproduction and transformation. The methodological approach makes visible the ways in which everyday practices are imbedded in practices of domination. It also shows how the struggle of the organization is primarily a struggle against the reproduction of these structures. The analysis of social and gender relations, as structures of domination, indicates how organizational practices are socially constructed and rooted in deep structures which made the researchers take for granted the way in which reality presented itself in their experience.

The transformation of organizational practices is fundamentally related to the development of critical consciousness. Popular education was examined as praxis which aims at consciousness raising. It was argued that some crucial aspects must be considered in the development of critical consciousness. First, it is important to identify oppression in everyday relations, for everyday life is what fundamentally defines us in the world. Second, it is important to identify forms of resistance. Here, the development of conflictual relations is central to the development of forms of opposition. Political subjects are constituted when they enter into conflictual relations which challenge structures of domination. Third, there must be a process where experiences and resistance are collectivized. It is important to look at structures of domination as socially constructed. The structural dimension of domination must be understood. The realm of everyday life is transcended by the macro structures of society. Fourth, there is a development of alternative practices, a process in which the intentionality of transformation comes into focus.

The development of critical consciousness in Maria Goretti and in other grass roots organizations suggested a reconceptualization of consciousness which makes a distinction between consciousness in discourse and consciousness in action. Those who understand consciousness as the expression of change in a particular kind of discourse which is identified as political, typically ignore the 
transformative action of those who have not articulated their experience in this discourse. The oversight applies, in particular, to the participants of the organization in the marginal sectors, especially women. In this study, by contrast, action has been taken as a significant indicator of critical consciousness.

The reconceptualization of critical consciousness is linked to a reconceptualization of the political. It is argued that the experience of Maria Groretti reveals the fundamentally political character of their process of development. The reconceptualization of the political has implied a critique of the public/private split and of its consequent identification of the political in the public sphere. It is argued that hegemony is reproduced through everyday practices. Therefore, the question of power is shifted, from external structures which determine our everyday life, to an everyday in relation to the macro structure. Within this perspective, those forms of struggle found in Maria Goretti which resist oppression in the private sphere are political struggles. Popular education, although being with these forms of struggle, needs to deepen its conceptualization of the political. The development of critical consciousness is crucial to an understanding of how to work politically in education.

The development of a transformative organizational praxis needs to be related to a macro level; a relation with the macro level must be established. In this study, it is argued that local development of an adequate perspective which provides a framework to relate microexperiences to broader instances of coordination are especially important in terms of the construction of a popular education project. It is assumed that no microexperiences will be successful if they are not related to higher levels of organization and coordination, that is, to the level of a social movement. The idea of local development adequately addresses the relation between everyday organizational practices and a concept of decentralized development which allows a higher degree of autonomy for organizations to implement their programs. Central to this study was the need to understand organizational practices from the point of view of the participants by developing an ethnographic case study and a multiple interpretation of the case. The decoding of the cultural significance of the organizational practices was an important part of the process of interpretation. This is the reason why the researcher has attempted to use the words of the participants and has used a considerable number of quotations from Maria Goretti's members as well as from those other interpreters who shared a similar cultural background. The interpretation attempted to provide an argument about how and why one understands Maria Goretti as a process of transformation of organizational practices. 
The Interpretative Argument as Put Forth in the Football Study

In the Rules for Disorder study the researchers understand their account as one that is backed by argument. In fact, their argument attempts to counter media interpretations of youth violence as arbitrary and anarchic. They venture into their own argument at two levels. The first is that of a structural articulation of rules interpreting violence at the school and football games of working class youth. Here the concept of moral careers was introduced and was ventured as a central reason for action. They talk about "moral careers" as conventional accounts. They then shift to what they say is a causal account embedded in naturalistic explanation. The sociobiological concept of aggro is presented as a causal mechanism for violence in these settings. Thus for these researchers the ethnographic work is filtered through conventional categories of social science, that is, structural concepts (i.e., moral careers) and functional concepts (i.e., aggro). As was said earlier in the paper, critical interpretation, as a way of resymbolizing the world of others, requires a sensitivity in reflecting back to the participants and other interested parties (i.e., social scientists and social policymakers, etc.) their capacities for "intentional intervention" (i.e., free acts of agents creating a world). The Rules for Disorder study clearly lacks this critical moment in its argument. The functional concept of aggro, for example, themetizes the participants' actions within a biological framework and thus ignores the agent's quality of aggression and the possible truth that rebellion is more than ritual liability. Thus within this frame of reference, the researchers interpret resistance and aggression as a biological process rather than a form of intentional intervention in societal processes.

This concludes our comparative analysis of two ethnographic studies. If we have demonstrated that ethnographies embrace different theories and research practices, even when they are seen as replacing mainstream quantitative analysis, then we have succeeded in our task.

\section{References}

Campbell, D. (1986). Enhancing collective belief change and the problems of the social sciences. In D.W. Fiske \& R.A. Shweder (Eds.), Metatheory in the social sciences. Chicago: University of Chicago Press.

Giddens, A. (1979). Central problems in social theory. Toronto: Macmillan.

Harre, R., \& Secord, P. (1971). The explanation of social behavior. Oxford, England: Blackwell.

Hirsch, E.D. (1976). Validity in interpretation. New Haven, CT: Yale University Press.

March, P., Rosser, E., \& Harre, R. (1978). The rules for disorder. London: Routledge. 
Martinic, S. (1984). Educacion y cambio social. Santiago, Chile: CIDE.

Ricoeur, P. (1978). Explanation and understanding. In C. Reagan \& D. Stewart (Eds.), The philosophy of Paul Ricoeur. Boston, MA: Beacon Press.

Schon, D. (1983). The reflective practitioner. New York: Basic Books.

Sullivan, E.V. (1984). Critical psychology: Interpretation of the personal world. New York: Plenum Press.

Sullivan, E.V. (in press). Common sense: The foundations for social science. In F. Van Holthon \& D. Olson (Eds.), Common sense. Maryland: University of America.

Touraine, A. (1981). The voice and the eye. New York: Cambridge University Press.

Walker, H. (1986). The transformation of practices in grass-roots organizations: A case study. Unpublished doctoral dissertation, University of Toronto.

Willis, P. (1977). Learning to labor. Hampshire, England: Teakfield.

Zuniga, R. (1986a, March). Investigacion cientifica y práctica profesionales: Una refleccion epistemologica. Paper presented at the University of Puerto Rico.

Zuniga, R. (1986b). Evaluateurs, chercheurs et travailleurs sociaux. Unpublished paper, Montreal. 